\title{
VIBRATION TESTING FOR ASSESSING THE HYDRO UNIT CONDITION IN DIFFERENT OPERATING MODES
}

\author{
Davorka Šaravanja \& Marko Grbešić
}
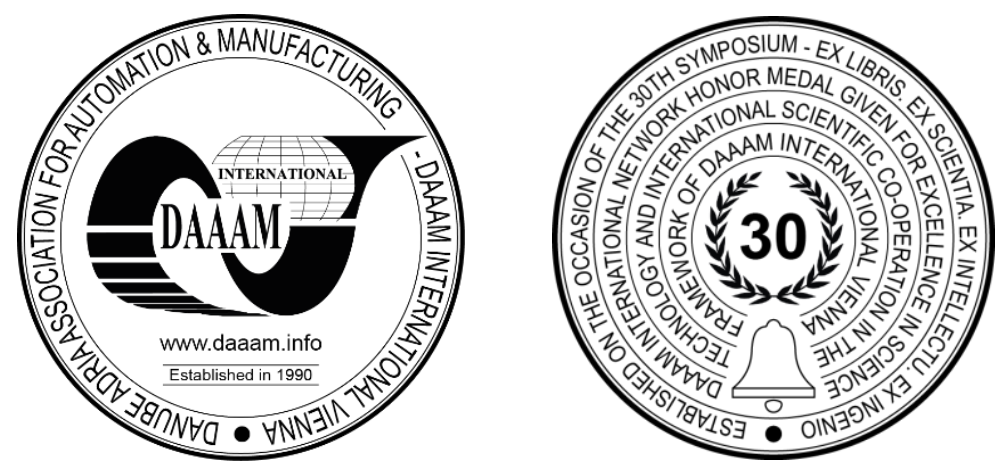

This Publication has to be referred as: Saravanja, D[avorka] \& Grbesic, M[arko] (2020). Vibration Testing for Assessing the Hydro Unit Condition in Different Operating Modes, Proceedings of the 31st DAAAM International Symposium, pp.0019-0026, B. Katalinic (Ed.), Published by DAAAM International, ISBN 978-3-902734-29-7, ISSN 1726-9679, Vienna, Austria

DOI: $10.2507 / 31$ st.daaam.proceedings.003

\begin{abstract}
This paper presents research on vibration parameters and comparison of vibration amplitude testing before and after overhaul of a hydro unit. The vibration test program is based on the international standards ISO 7919:5(2005) and ISO 10816:5(2000), which evaluate the vibration of the machine by measurements at the appropriate positions of the rotating and non-rotating elements. The evaluation criteria were: the magnitudes of the measured vibration and the changes in the magnitude of the measured vibration. In doing so, sensors installed in two directions, in the direction of water flow and perpendicular to that direction, were used. The measured parameters used to check for elevated vibrations are two types of vibration displacement amplitude and vibration velocity amplitude on the most endangered bearings. Measurements were performed in several different operating modes in which previous tests, before the rehabilitation of the facility, indicated the appearance of irregularities and an increased risk of continued operation of the tested facility. The analysis of the measured results showed that the prescribed criteria for safe operation of the unit were provided.
\end{abstract}

Keywords: hydroaggregate; vibration; measurement; displacement; velocity

\section{Introduction}

Over the past decades, many hydropower plants have changed the regime of continuous operation with a base load to modes with periodic and partial workload. Operating modes with periodic and partial workloads have been shown to be more cost-effective from an economic point of view, but they additionally burden production units due to the increased start/stop frequency. It is therefore important to implement an effective safety and condition monitoring solution to ensure that errors are detected in a timely manner and to avoid catastrophic failures and consequent downtime.

Today's way of life requires high efficiency of hydropower plants in delivering electricity. Therefore, hydropower plants must be fully operational, and that requires a very good strategy of monitoring the technical condition of the plant to satisfy very high user requirements. 
One of the important goals of proactive maintenance of a hydro unit is to be familiar with its technical condition, to intelligently plan interventions using vibro-diagnostic methods, to identify errors before remediation and to correct errors after it. The purpose of this paper is to present the optimal diagnostic system applicable to the hydroagregate, which is designed to measure, monitor, diagnose vibrations and analyze the technical and functional parameters associated with them for the safe use of the hydro-unit turbine. This concept of proactive maintenance is increasingly used in practice due to the improvement and development of such systems for monitoring, analysis and control of vibrations, all in order to prevent longer interruptions caused by failures [1].

In the context of developing more modern technologies of production, assembly, testing and operation of hydro aggregates, proactive maintenance of the same based on the assessment of the state of vibration plays an important role in reducing operating costs and increasing competitiveness. The advantages of this maintenance technology applied to hydropower plants are the continuous monitoring of normal operating parameters required for a stable mode of operation (especially when starting or stopping the plant). Analysis of measured vibration parameters that are within normal limits allows safe operation to continue, and exceeding normal limits indicates the occurrence of irregularities whose development and expansion can lead to even greater failures and power outages, high costs of power outages and high repair and renovation costs [2].

The aim of this paper is to demonstrate the application of this technology in order to check whether the increased vibration amplitudes on the most endangered bearings in several different operating modes have exceeded the level compared to previous tests and are within limits that ensure safe operation.

\section{Hydroaggregate vibration causes}

The main sources of vibration in objects such as hydroaggregates are most often misalignment with the shaft line, mass imbalance, bearing damage, mechanical looseness and the occurrence of hydrodynamic, electrical and magnetic forces. Such irregularities, whether within the permissible limits or outside them, generate vibrational components at the frequency of rotation with accompanying harmonics and subharmonics, Fig. 1. Damage and mechanical looseness on bearings also occur due to normal operation during use, but also as a consequence of other irregularities such as oil film turbulence and problems with unsuitable lubrication system [3].

Imbalance and misalignment can be caused by uneven distribution of mass on the various components of the rotating assembly or by improperly mounted parts and joints. Other types of irregularities caused by the occurrence of different types of forces are related to specific parts of hydroaggregates, mainly to electric generators and turbines. In this case, they are stated in general and are not known at the level of complexity of the test object, which indicates additional and more detailed tests and data for the formation of even more effective diagnostic criteria for hydroaggregates. Table 1 . shows the main causes of vibrations as a function of frequency which are a very useful tool for problem identification.

\begin{tabular}{|c|c|c|c|c|c|c|c|c|c|c|c|}
\hline \multirow{2}{*}{\multicolumn{2}{|c|}{ The main causes of vibrations }} & \multicolumn{10}{|c|}{ Relative vibration frequencies } \\
\hline & & \multirow{2}{*}{ 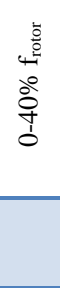 } & \multirow{2}{*}{ 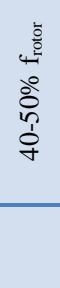 } & \multirow{2}{*}{ 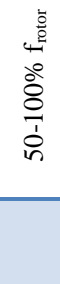 } & \multirow{2}{*}{ 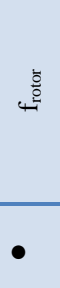 } & \multirow{2}{*}{ 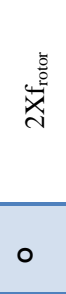 } & \multirow{2}{*}{ 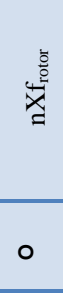 } & \multirow{2}{*}{ 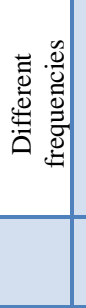 } & \multirow{2}{*}{ 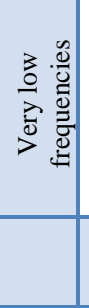 } & \multirow{2}{*}{ 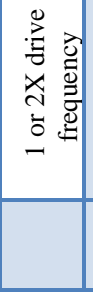 } & \multirow{2}{*}{ 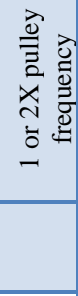 } \\
\hline Imbalance & $\begin{array}{l}\text { Improper mass distribution of } \\
\text { rotating components }\end{array}$ & & & & & & & & & & \\
\hline \multirow{4}{*}{$\begin{array}{l}\text { Misalignment and } \\
\text { deformation errors }\end{array}$} & Misalignment errors & & & & $\bullet$ & $\bullet$ & o & & & & \\
\hline & Base deformation & & o & & $\bullet$ & o & o & & & & \\
\hline & Bearing housing deformation & o & 0 & o & $\bullet$ & o & & & & & \\
\hline & Axial rotor contact & o & o & o & $\bullet$ & o & $\circ$ & $\circ$ & $\circ$ & o & o \\
\hline \multirow{3}{*}{$\begin{array}{c}\text { Bearing damage and } \\
\text { deformation of the journal } \\
\text { bearing }\end{array}$} & $\begin{array}{l}\text { Bearing damage with roller } \\
\text { elements }\end{array}$ & & & & $\circ$ & & & $\bullet$ & $\circ$ & & \\
\hline & Damage to the base bearing & $\bullet$ & $\bullet$ & $\bullet$ & $\bullet$ & $\bullet$ & & & & & \\
\hline & Eccentricity of the bearing & & & & $\bullet$ & & & & & & \\
\hline \multirow{3}{*}{$\begin{array}{c}\text { Electrical and magnetic } \\
\text { problems }\end{array}$} & Asymmetric stator & & & & & & & & & $\bullet$ & \\
\hline & Asymmetric rotor & $\bullet$ & & & & & & & & & \\
\hline & Eccentric air clearance & \multicolumn{8}{|c|}{ Depending on the construction characteristics } & & \\
\hline Pulley damage & Eccentric pulleys & & & & & & & $\circ$ & & & $\bullet$ \\
\hline Resonance & $\begin{array}{c}\text { Resonance of the structure, } \\
\text { supports, frames and structural } \\
\text { elements }\end{array}$ & \multicolumn{10}{|c|}{ It can be induced over the entire frequency range } \\
\hline
\end{tabular}




\begin{tabular}{|c|c|c|c|c|c|c|c|c|c|c|}
\hline & $\begin{array}{l}\text { Critical rotational speeds of the } \\
\text { rotor or system rotor / bearing }\end{array}$ & & & & $\bullet$ & & & & & \\
\hline $\begin{array}{c}\text { Aerodynamic and } \\
\text { hydrodynamic forces }\end{array}$ & & & & & $\circ$ & & $\bullet$ & & ० & \\
\hline \multirow{4}{*}{ Oil film instability } & Oil whirl & & $\bullet$ & & & & & & & \\
\hline & Oil whip & & $\bullet *$ & o & & & & & & \\
\hline & Friction caused by instability & $\bullet$ & $\circ$ & o & & & & & & \\
\hline & Excitation due to air clearance & o & $\bullet$ & o & & & & & & \\
\hline \multirow{2}{*}{$\begin{array}{c}\text { Gear and coupling } \\
\text { problems }\end{array}$} & Gears damage & & & & & & ○ & $\circ$ & $\bullet$ & \\
\hline & Coupling damage & & o & & o & o & $\bullet$ & & & \\
\hline $\begin{array}{l}\text { Vibrations caused by the } \\
\text { action of adjacent machines }\end{array}$ & & \multicolumn{9}{|c|}{ They can occur over the entire frequency range } \\
\hline $\begin{array}{l}* \text { appear only when } \\
f_{\text {rotor }}>2 \mathrm{xf}_{\text {crit.(rotor) }}\end{array}$ & & \multicolumn{9}{|c|}{$\begin{array}{c}\bullet=\text { characteristic vibration frequency } \\
\circ=\text { vibration frequencies that may occur in addition to } \\
\text { characteristic vibration frequencies }\end{array}$} \\
\hline
\end{tabular}

Table 1. The main causes of vibrations as a function of frequency

\section{Description of hydroaggregates as an object of vibrodiagnosis}

Pump-turbine motor-generator hydroaggregate of vertical construction consists of a pump-turbine (KAPLAN turbine TK 5-4,00 technical minimum power of $12 \mathrm{MW}$, nominal rotation speed of $\mathrm{n}_{\text {nom }}=150 \mathrm{~min}^{-1}$ installed water flow $\mathrm{Q}=120 \mathrm{~m}^{3} / \mathrm{s}$, and the minimum $\mathrm{Q}=50 \mathrm{~m}^{3} / \mathrm{s}$. and the degree of efficiency $\eta=93.5 \%$ ) and the motor-generator with a vertical shaft connected by a rigid coupling (type S6546-40, P $=30 \mathrm{MVA}, \mathrm{U}=10.5 \mathrm{kV}, \mathrm{I}=1650 \mathrm{~A}, \mathrm{f}=50 \mathrm{~Hz}$ and number of poles 40). It has two modes of operation: the hydraulic machine works as a turbine and as a pump, and the electric machine as a generator and as a motor. The mode of rotation of the rotor is different depending on the operating mod [4]. The entire rotor carries the upper axial-radial bearing, and the radial guidance is achieved by the upper (generator-motor) and lower (turbine-pump) radial bearings [3]. Schematic and photographic representation of individual parts of the hydroaggregate with selected measuring points can be found in Fig. 1.
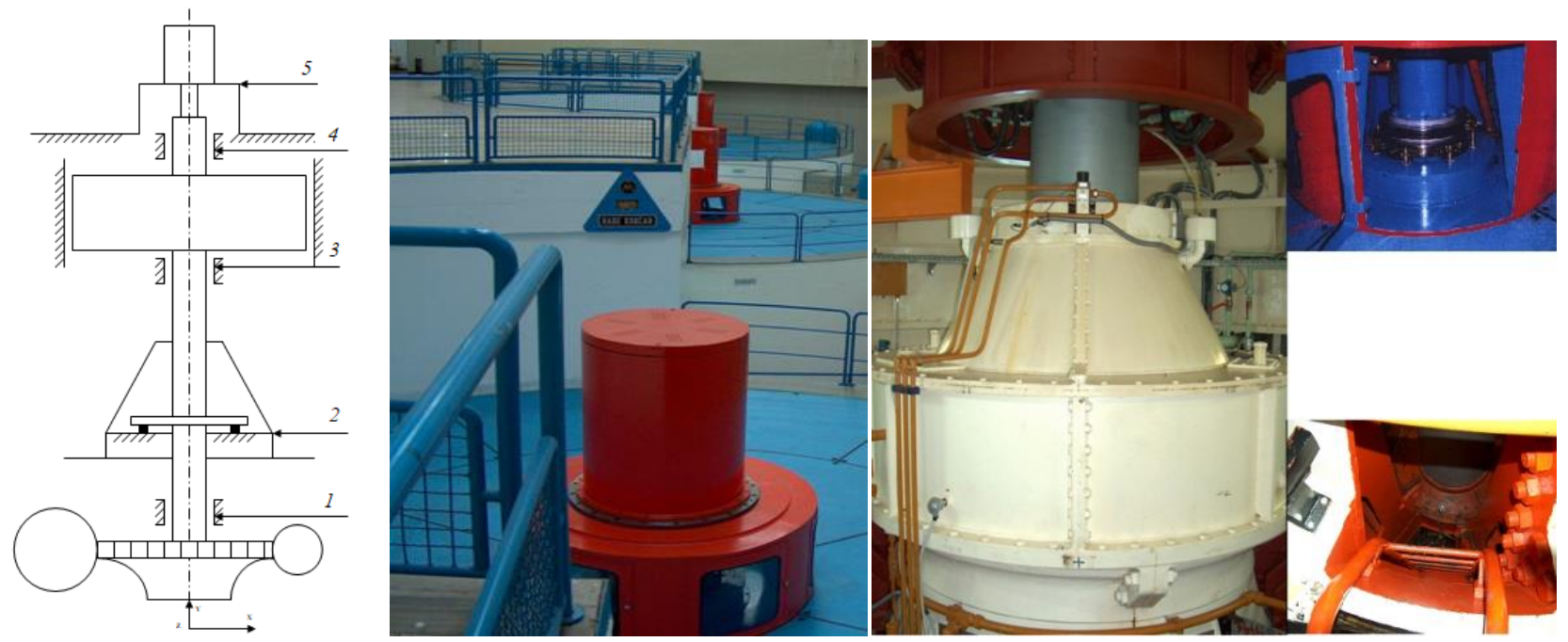

Fig. 1. Schematic and photographic representation of the hydroaggregate

Measurement of absolute vibration quantities was performed at 5 measuring positions in the directions: $\mathrm{x}$-radial (horizontal), y-radial (horizontal) perpendicular to $\mathrm{x}$, z-axial (vertical), and relative shaft vibrations on the two main bearings (upper and lower) (Fig. 1).

Measurements were performed under the following operating conditions / loads [5]:

- mechanical rotation,

- self-excited generator

- at load $\mathrm{P}=12 \mathrm{MW}$,

- at load $\mathrm{P}=16 \mathrm{MW} \mathrm{i}$

- at load $\mathrm{P}=25 \mathrm{MW}$. 
As indicators of the vibration condition on the hydroaggregate with the most information on defect signs, according to ISO 7919-5 and ISO 10816-5 (new ISO 20816-5: 2018) [6]: were selected for measuring parameters: absolute and relative vibrations of bearings and shafts of the unit, and their [7][4][8][9]:

- peak-peak values $s_{\max }$, ie. $p$-p values of vibration displacement in $\mu \mathrm{m}$,

- effective vibration velocities $\mathrm{v}_{\mathrm{ef}}$ in $\mathrm{mm} / \mathrm{s}$ or $\mathrm{rms}$

for which frequency analysis was also

In Fig. 2. some of the vibration spectra recorded at the measuring points of the hydroaggregate after the remediation are shown. The change of the peak-peak value $s_{\max }$, ie. $p$-p value of the vibration displacement in $\mu \mathrm{m}$ in each operating mode on each selected bearing is shown. Statistical processing of this data is particularly pronounced as a useful tool for diagnosing future work, and relates to vibration monitoring and the formation of a database for comparison in the following tests.

\subsection{Data collection system}

For acquisition and measurement of vibrations, analysis and display of analysis results, a vibration measuring instrument type VIBROTEST 60-Brüel \& Kjær Vibro was used, which is recommended for use in the EU, and for the appropriate frequency range the corresponding contact sensor-accelerometer for absolute vibration measurement in accordance with ISO 10816 -5 (type AC 065 AS-06X / 07X) [10] and contactless sensors for measuring relative vibrations in accordance with ISO 7919-5 (type Truck Ni5-M12-LiU H1141) [11]. This instrument allows a special combination of measurement functions, and thus several different types of applications. VIBROTEST 60 is an ideal instrument for measuring the vibration response because, due to its multiple function,s it is also a "diagnostic expert" with solutions for general application. The main advantages of this instrument are:

- at the same time represents an instrument for measuring vibration amplitude, FFT analyzer and balancer for balancing;

- compact and very light (approx. $900 \mathrm{~g}$ );

- enables two-channel measurement and processing of random data from them;

- has a digital signal processor (DSP);

- has high measurement accuracy and dynamic resolution with analog-to-digital conversion (16 Bit ADC);

- performs FFT spectrum analysis with a resolution of max. 12,800 frequency lines;

- uses standard sensors for vibration displacement, velocity and acceleration;

- has a high-contrast graphic display with a light background;

- has a huge memory capacity, and allows data protection with a PC card (Compact Flash / PCMCIA), which is used to store data and the corresponding frequency spectra.

By applying the modular structure of the hardware part of this instrument, the condition of the machine can be determined very quickly by measuring the relevant parameters and comparing them with the limit values or forming, the so-called measurement trend for a certain period. It is especially important to point out the possibility of entering all the observed and important indicators of machine condition. The result of the data processing conclusions is diagnostic information that decides whether the facility can continue to operate or whether the necessary repairs need to be performed.

Basic Module 1.1 allows the measurement of: absolute vibrations on bearings; relative shaft vibrations; BCU (Bearing Condition Unit) in a wide frequency range.

Module 1.2 performs the functions of measuring overall vibrations in relation to speed and overall vibrations in relation to time (Overall Vibration vs. Speed, Overall Vibration vs. Time), giving the possibility of estimating the state of the object for a certain period of time. The most important features of Module 1.2 are:

- All measurement results are stored on measurement lists, stored and displayed via the so-called Listing Function.

- "Report" memory has unlimited capacity thanks to the PC Card. A PC card is used for data transfer, which allows you to read data by simply inserting it.

- Viewing the time period greater than 24 hours is possible via the maximum amount of data (greater than 6,400) on the record in relation to the time.

- Flexible frequency scale configuration allows the use of different narrowband and broadband frequency filters for more extensive measurements, which guarantees optimal adaptation to special measurement tasks.

- Simultaneous processing of vibration parameters related to the condition of the bearings.

- Eliminate the effects of beating or pulsing due to noise.

Module 2.1. enables obtaining the frequency spectrum based on vibration amplitude measurements, ie. displaying the frequency spectrum and representing the vibration amplitude according to the linear or logarithmic frequency axis, with the possibility of selecting the band on the frequency axis, using the VIBRORAPORT option (Fig. 2). 

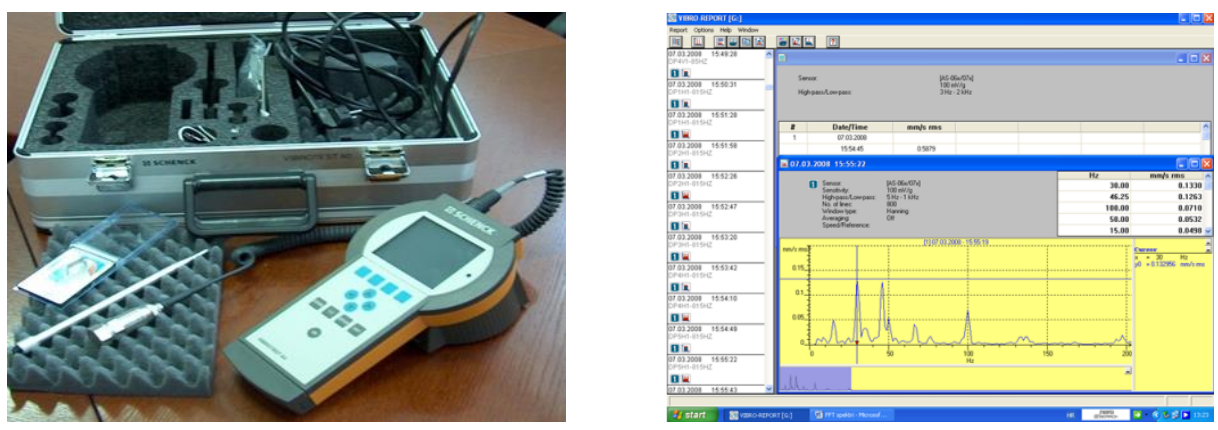

Fig. 2. Measuring equipment and an example of the frequency spectrum from the measuring point

\subsection{The standards for the evaluation of vibration}

To estimate the total value of the relative vibration displacement, ISO 7919 (1-5) standards developed on the same principles as ISO 10816 standards for estimating the total vibration velocity measured on static machine parts are applied. Their application estimates the peak-to-peak displacement value (or $S_{\max }$ value). A significant difference between these two standards is the fact that the acceptable relative and absolute vibration displacement of the shaft depends on the operating speed of the machine (Fig. 3).

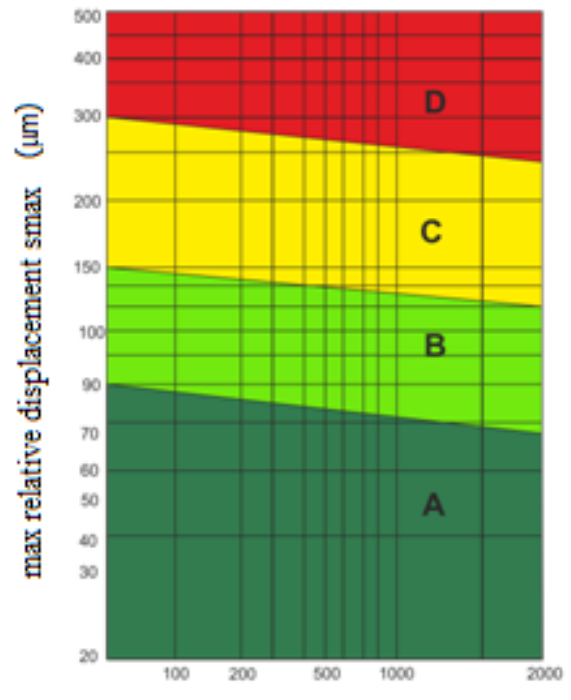

max rotation speed rms

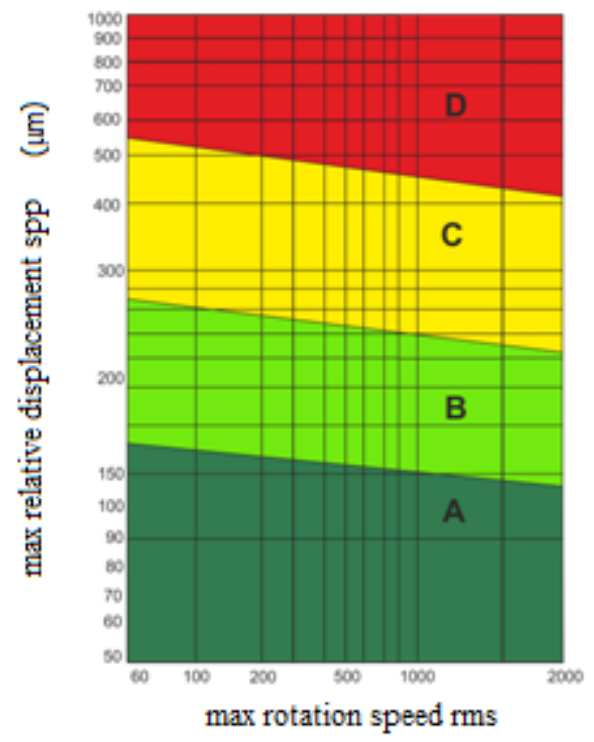

max rotation speed $\mathrm{rms}$

Fig. 3. ISO 7919-5

ISO 10816 standard provides guidelines for assessing machine condition for different types of machines based on two criteria: vibration magnitude and vibration magnitude change. According to ISO 10816 standard, the best way to meet both criteria is to measure and compare the measurement results before and after the rehabilitation of the test object. ISO 10816 standard is based on the measurement of the total root mean square value of the vibration velocity (rms) in the frequency range from 10 to $1000 \mathrm{~Hz}$. This standard defines the assessment of the zone of (un)acceptable level or magnitude of vibration amplitude. Based on the range of amplitude of vibration parameters, machines can be classified according to their condition into one of four zones:

- zone A-vibrations of machines that have just been put into operation usually belong to this zone;

- zone B-vibration machines within this zone are considered acceptable for unrestricted operation;

- zone $\mathrm{C}$-vibrating machines within this zone are considered unacceptable for long-term continuous operation and in this state can only operate for a limited time until a favorable opportunity for further operation is created;

- zone D-the vibration values within this zone are considered strong enough to damage the machine [12].

Classification of the machine according to the indicated zones helps in deciding on the future operation of the machine and predicting the necessary actions (current shutdown, operation until the next planned repair, etc.). Restriction zones are indicative values more than strict rules and can be adapted to other decisions, such as those made based on the experience of the manufacturer or user. Table 2. shows the recommended limits of measuring parameters for the evaluation of machines of group 3, which include hydroaggregates as vertical machines with bearing housings connected to rigid foundations with an operating speed between 60-1800 rpm. 


\begin{tabular}{|c|c|c|c|}
\hline \multicolumn{2}{|c|}{ Machine } & \multicolumn{2}{c|}{ Hydroaggregate 150 rpm, P=12 MW } \\
\hline \multirow{2}{*}{} & Measurement parameter & $\begin{array}{c}\text { Vibration velocity mm/s, } \\
\text { rms }\end{array}$ & $\begin{array}{c}\text { Vibration displacement } \\
\mu \mathrm{m}, \mathrm{p}-\mathrm{p}\end{array}$ \\
\hline \multirow{3}{*}{$\begin{array}{c}\text { Perfomance } \\
\text { ratings }\end{array}$} & A-Good & $<1,6$ & $<30$ \\
\cline { 2 - 4 } & B-usable & $1,6-2,5$ & $30-50$ \\
\cline { 2 - 4 } & C-Admitted under supervision & $2,5-4$ & $50-80$ \\
\hline
\end{tabular}

Table 2. Evaluation of efficiency in accordance with ISO 10816-5: 2000

\subsection{Vibration test and analysis results}

Tables 3. and 4. show the parameters that describe the level of vibration on the tested HA at different operating modes.

\begin{tabular}{|c|c|c|c|c|c|}
\hline \multicolumn{6}{|c|}{ Mechanical rotation } \\
\hline $\begin{array}{l}\text { Measuring } \\
\text { position: }\end{array}$ & MP-1 & MP-2 & MP-3 & MP-4 & MP-5 \\
\hline $\begin{array}{l}\text { Measurement } \\
\text { direction: }\end{array}$ & \multicolumn{5}{|c|}{ Measured values of vibration displacement $S_{\max }(\mu \mathrm{m})$} \\
\hline $\mathrm{x}$ & 16,2 & 18,4 & 9,4 & 5,5 & 7,3 \\
\hline $\mathrm{y}$ & 18,1 & 22,3 & 8,7 & 4,3 & 8,4 \\
\hline $\mathrm{z}$ & 19,7 & 28,5 & 7,3 & 7,7 & 8,2 \\
\hline \multicolumn{6}{|c|}{ Self-excited generator } \\
\hline $\begin{array}{l}\text { Measurement } \\
\text { direction: }\end{array}$ & \multicolumn{5}{|c|}{ Measured values of vibration displacement $\mathrm{s}_{\max }(\mu \mathrm{m})$} \\
\hline $\mathrm{x}$ & 17,1 & 21,2 & 11,2 & 9,5 & 8,1 \\
\hline $\mathrm{y}$ & 18,3 & 22,3 & 9,4 & 8,4 & 9,5 \\
\hline $\mathrm{z}$ & 21,2 & 32,6 & 8,6 & 8,3 & 8,6 \\
\hline \multicolumn{6}{|c|}{ at load $\mathrm{P}=12 \mathrm{MW}$} \\
\hline $\begin{array}{l}\text { Measurement } \\
\text { direction: }\end{array}$ & \multicolumn{5}{|c|}{ Measured values of vibration displacement $\mathrm{S}_{\max }(\mu \mathrm{m})$} \\
\hline $\mathrm{x}$ & 10,4 & 23,4 & 9,5 & 9,5 & 8,4 \\
\hline $\mathrm{y}$ & 9,4 & 29,8 & 9,5 & 8,3 & 9,5 \\
\hline $\mathrm{z}$ & 16,3 & 33,3 & 8,3 & 9,4 & 8,5 \\
\hline \multicolumn{6}{|c|}{ at load $\mathrm{P}=16 \mathrm{MW}$} \\
\hline $\begin{array}{l}\text { Measurement } \\
\text { direction: }\end{array}$ & \multicolumn{5}{|c|}{ Measured values of vibration displacement $s_{\max }(\mu \mathrm{m})$} \\
\hline $\mathrm{x}$ & 9,2 & 20,1 & 9,5 & 8,7 & 8,5 \\
\hline $\mathrm{y}$ & 9,3 & 25,4 & 10,1 & 7,6 & 9,8 \\
\hline $\mathrm{z}$ & 15,4 & 27,5 & 8,2 & 6,8 & 7,5 \\
\hline \multicolumn{6}{|c|}{ at load $\mathrm{P}=25 \mathrm{MW}$} \\
\hline $\begin{array}{l}\text { Measurement } \\
\text { direction: }\end{array}$ & \multicolumn{5}{|c|}{ Measured values of vibration displacement $\mathrm{Smax}(\mu \mathrm{m})$} \\
\hline $\mathrm{x}$ & 15,3 & 24,6 & 9,5 & 9,5 & 8,1 \\
\hline $\mathrm{y}$ & 9,2 & 29,7 & 10,4 & 7,3 & 8,2 \\
\hline $\mathrm{z}$ & 17,1 & 32,3 & 9,5 & 8,5 & 8,2 \\
\hline \multicolumn{6}{|c|}{ Measured values of vibration velocity vef in $\mathrm{mm} / \mathrm{s}$ (rms) } \\
\hline $\mathrm{x}$ & 0,43 & 0,83 & 0,32 & 0,11 & 0,26 \\
\hline $\mathrm{y}$ & 0,42 & 0,56 & 0,33 & 0,24 & 0,25 \\
\hline $\mathrm{z}$ & 0,54 & 0,86 & 0,37 & 0,24 & 0,34 \\
\hline
\end{tabular}

Table 3. Measured values of absolute vibrations on the bearing housing at the measuring positions

\begin{tabular}{|c|c|c|}
\hline \multirow{2}{*}{ Operating modes / loads } & \multicolumn{2}{|c|}{ Relative shaft vibrations in $\mu \mathrm{m}$} \\
\cline { 2 - 3 } & Upper guide bearing & Lower guide bearing \\
\hline Mechanical rotation & 77 & 79 \\
\hline Self-excited generator & 81 & 76 \\
\hline at load $\mathrm{P}=12 \mathrm{MW}$ & 78 & 75 \\
\hline at load $\mathrm{P}=16 \mathrm{MW}$ & 69 & 66 \\
\hline at load $\mathrm{P}=25 \mathrm{MW}$ & 68 & 71 \\
\hline
\end{tabular}

Table 4. Measured values of relative shaft vibrations on the upper and lower bearing HA 
The analysis of the measured results from Tables 3. and 4. is presented in graphs showing the change of peak-peak values of vibration displacements $(\mu \mathrm{m})$ according to different operating modes of hydroaggregates at measuring positions (Fig. 4a) and change of effective values of vibration velocity in $(\mathrm{mm} / \mathrm{s})$ in all directions in relation to the measuring positions at the maximum load of the hydroaggregate (Fig. 4b).
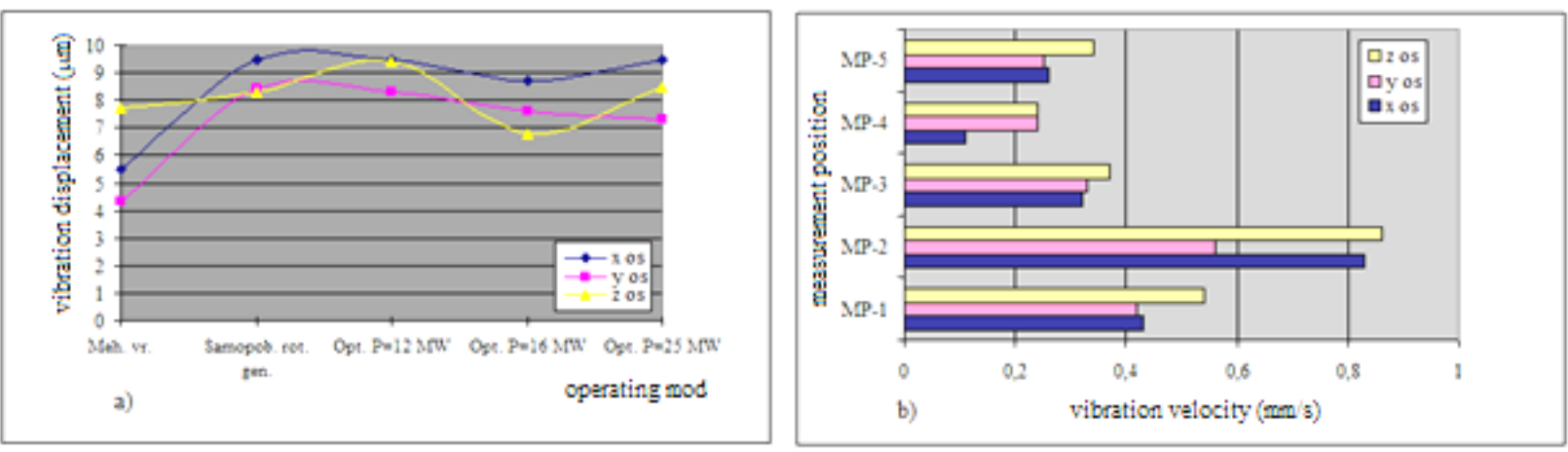

Fig. 4. Analysis of results showing the dependence of the measured parameter on the operating mode

\section{Conclusion}

According to the recommendations of the department for maintenance of hydroaggregates as a test facility, it was determined that, in order to assess its technical condition, among other tests, it is necessary to perform vibration testing at characteristic places and locations with appropriate instruments and equipment recommended by ISO 7919 and ISO 10816 before and after as part of the semi-annual review. Based on the measurement results (shown in Tables 3 and 4 ) it was determined that, according to the guidelines on permissible vibrations of such rotary machines, which belong to the group of machines 3 ISO 10816, the measured absolute vibration values at all measuring positions are in zone B for different operating modes and no association was found in the behavior of the machine for a specific operating mode. According to ISO 7919-5, the values of relative vibrations $s_{\max }$ in $\mu \mathrm{m}$ are in the acceptable range/zone A. Also, the application of measurements and analysis of vibrations did not show a sharp increase in vibration amplitudes compared to the previous measurement before remediation.

Using the instrument, the frequency analysis and separation of the vibration characteristics shown on the frequency spectra were performed (Fig. 2). The frequency spectra for the measuring positions in the given directions are of normal and usual appearance for such types of hydroaggregates, ie. for such types of water turbines. After the analysis and review of the graph, there appears to be an increase in the peak-peak values of vibration displacement in $(\mu \mathrm{m})$ in all directions and at all operating modes at the measuring position MP-2, which corresponds to the axial bearing, or an increase in effective values of vibration velocity at the measuring position MP-2 in all directions, and mostly in the axial, but only at the highest load, which is not common in operating conditions.

By extracting the vibration characteristics from the frequency spectra, the largest harmonics can be observed, which correspond to the fundamental frequency of rotation, but their amplitude values are still within the normalized allowable limits according to the results obtained before remediation. Therefore, all values of the measured parameters on the bearing housings and the shaft are acceptable for further operation of the unit.

Since the vibrations at the measuring position MP2 are elevated compared to other measuring points, it is recommended that in the following tests measurements of vibration waveform / shape in orbit be made in order to remove doubts about the correctness of measuring relative vibrations with non-contact sensors. In this regard, it is recommended to perform the roughness treatment $\mathrm{Ra}$ on an area of about $40 \mathrm{~mm}$ in the reading area with non-contact sensors for each bearing for some future, more accurate vibration measurements.

\section{References}

[1] C. W. de Silva. (2007). Vibration Fundamentals and Practice, Taylor \& Francis Group, , ISBN 0-8493-1987-0, London-New York.

[2] Harris, C.M.; Piersol, A.G. (2002). Harris' shock and vibration handbook, McGraw-Hill Professional, ISBN 0-07137081-1, New York.

[3] Veres, M.; Turcan, R.; Dumitrescu, D. (2011). Critical Analysis Of Vibration Sources Of Hydro Aggregates In Operating Regime, Journal Of Sustainable Energy Vol. 2, No. 4, December, 2011, University of Oradea, ISSN 2067-5534 (C) 2011 JSE.

[4] http://www.vibsens.com/iso10816-charts/ Accessed on: 2020-07-28 
[5] Kumar, A.; Gandhi, B.K.; Chandra, P.: Experience of Vibration and Noise Measurements of Small Hydro Power Plants, Indian Institute of Technology Roorkee, Roorkee-247 667, India, Available from: http://www.ighem.org/Papers_IGHEM/547.pdf, Accessed: 2020-06-28

[6] Nässelqvist, M.; Gustavsson, R.K.; Aidanpää, J.O. (2013). A Methodology for Protective Vibration Monitoring of Hydropower Units Based on the Mechanical Properties, Journal of Dynamic Systems Measurement and Control 135(4):410071-410078, Available from: https://www.researchgate.net/publication/255689515

[7] https://www.sis.se/api/document/preview/19514/ Accessed on: 2020-07-28

[8] https://energiforskmedia.blob.core.windows.net/media/25312/hydro_nasselqvist.pdf, Accessed on: 2020-05-31

[9] Šaravanja, D.; Grbešić, M. (2019). Application of Vibration Analysis in Journal Bearing Problems Diagnostics, Proceedings of the 30th International DAAAM Symposium "Intelligent Manufacturing \& Automation", 23-26th October 2019, Zadar, Croatia, Volume 30, No.1 ISBN 978-3-902734-22-8, ISSN 1726-9679, Ed. B. Katalinic / Published by DAAAM International, Vienna, Austria, EU, 2019.

[10] https://www.bkvibro.com/fileadmin/mediapool/Internet/Instructions/Portable_instruments/VT60/vtest60e_V446ff.pdf, Accessed on: 2013-06

[11] https://www.turck.de/datasheet/_en/edb_1535535_gbr_en.pdf, Accessed on: 2020-07-28

[12] Šaravanja, D.; Petković, D. (2019). Technical diagnostics-methods of testing the structure and condition of the system, University of Mostar, ISBN 978-9958-16-131-5, Mostar. 